\title{
Implementasi Kebijakan Silvopastur di Cagar Alam Gunung Mutis dan Perlawanan Masyarakat Lokal
}

\author{
Rahman Kurniadi ${ }^{1}$ \\ Lukas Rumboko ${ }^{2}$
}

\begin{abstract}
This research begin from a question on why local communities resist on silvopasture policy; therefore, Forest is damaged potentially. Research use explorative qualitative methods to understand why local communities resist on silvopasture policy and access theory (Ribot $\mathcal{E}$ peluso, 2003) to understand whether local communities resistance affect silvopasture policy implementation. Primary data was collected through interview and observations of some grazers, government, entrepreneur and NGO. Results showed that local communities resist on silvopasture policy because the silvopasture policy didn't consider local context. Local resistance affect policy implementation because grazers have power to access forest which has grass as natural resource in Gunung Mutis reserved forest.
\end{abstract}

\section{Keywords:}

silvopasture; Mutis Reserved Forest; policy implementation; local resistance.

\begin{abstract}
Abstrak
Penelitian ini bertolak pada permasalahan yang melatarbelakangi masyarakat sekitar hutan tidak mengindahkan larangan silvopastur di dalam kawasan Cagar Alam Gunung Mutis sehingga berpotensi mengganggu kelestarian cagar alam tersebut. Metode yang digunakan adalah eksploratif kualitatif agar dapat memahami alasan masyarakat lokal melakukan perlawanan terhadap larangan silvopastur. Sedangkan pendekatan pendekatan yang dipakai adalah teori akses ( Ribot \& Peluso, 2003) untuk memahami berpengaruh atau tidaknya perlawanan terhadap kegagalan implementasi kebijakan silvopasture. Data primer dikumpulkan dengan cara wawancara dan observasi dari peternak, pihak pemerintah, LSM, dan pengusaha. Hasil penelitian menunjukan bahwa masyarakat melakukan perlawanan terhadap larangan silvopastur karena kebijakan tersebut tidak sesuai dengan konteks masyarakat lokal. Perlawanan tersebut berpengaruh pada impelementasi kebijakan silvopastur karena masyarakat lokal memiliki kemampuan untuk mengambil manfaat dari sumber daya alam berupa rumput yang di dalam Cagar Alam Gunung Mutis.
\end{abstract}

\section{Kata Kunci:}

Silvopastur; Cagar Alam Gunung Mutis; pelaksanaan kebijakan; perlawanan lokal.

\footnotetext{
1 Balai Penelitian Kehutanan Kupang.

Email: rahmankurniadi@gmail.com

2 Pusat Penelitian dan Pengembangan Perubahan Iklim dan Kebijakan.

Email: lrumboko@yahoo.com
} 


\section{Pendahuluan}

Kelestarian hutan sangat tergantung kepada masyarakat sekitar hutan (Gintings \& Lai, 1994). Untuk menjamin kelestariannya, pemerintah telah mengeluarkan peraturan yang mengatur perilaku masyarakat sekitar hutan. Salah satu peraturan yang dikeluarkan adalah larangan silvopastur di dalam cagar alam. Namun untuk kasus di Cagar Alam Gunung Mutis, peraturan tersebut tidak berjalan dengan baik. Masyarakat menggembalakan ternak secara liar di sana. Oleh karenanya, penelitian ini bertolak dari permasalahan yang menyebabkan masyarakat tidak mematuhi larangan silvopastur di Cagar Alam Gunung Mutis sehingga berpotensi mengganggu kelestarian cagar alam tersebut.

Berbagai penelitian telah dilakukan untuk memahami penyebab masyarakat sekitar hutan resisten terhadap kebijakan yang menyangkut sumber daya hutan. Namun hanya diperoleh sedikit informasi mengenai resistensi masyarakat terkait silvopastur di cagar alam. Penelitian ini menggunakan metode eksploratif kualitatif dan memilih teori akses (Ribot \& Peluso, 2003) untuk mendiskusikan berpengaruh atau tidaknya resistensi masyarakat lokal terhadap implementasi kebijakan silvopastur. Menurut teori akses, siapa yang dapat memanfaatkan hutan tidak tergantung kepada kepemilikan lahan, akan tetapi lebih tergantung pada kemampuan memanfaatkan sumber daya hutan. Menurut Ribot \& Peluso (2003) kemampuan suatu pihak dalam memanfaatkan sumber daya alam berhubungan dengan materi, budaya, dan kondisi sosial ekonomi pihak tersebut, sehingga tidak tergantung pada kepemilikan sumber daya alam.

Kerusakan hutan terjadi pada berbagai fungsinya yang meliputi hutan produksi, hutan lindung, cagar alam, taman nasional dan berbagai fungsi hutan lainnya (Naka et al., 2000). Hutan umumnya sulit dikontrol sehingga terjadi degradasi hutan (Zhou et al,
2014). Kerusakannya terjadi karena banyak kepentingan terhadap hutan (Wakka, 2014; Juerges, 2015). Terdapat banyak kepentingan dalam sumber daya hutan ( Purnomo, 2012).

Silvopastur telah lama dipraktikkan oleh masyarakat di Cagar Alam Gunung Mutis. Menurut Piggin (2003), silvopastur di Nusa Tenggara Timur mulai marak sejak Pemerintah Belanda mendatangkan sapi Bali tahun 1912. Hewan tersebut dapat beradaptasi dengan baik, namun demi mencukupi kebutuhan pakan ternak hutan dimanfaatkan untuk penggembalaan. Ketika kawasan hutan Gunung Mutis ditetapkan menjadi cagar alam tahun 1983, masyarakat setempat telah menggunakannya sebagai area penggembalaan ternak secara liar. Adanya sejarah penggunaan lahan mempersulit pihak Balai Besar Konservasi Sumber Daya Alam Nusa Tenggara Timur, selaku pihak yang bertanggung jawab atas kelestarian hutan, untuk mengeluarkan ternak dari Cagar Alam Gunung Mutis.

Setidaknya ada tiga kepentingan yang memperebutkan keberadaan Cagar Alam Gunung Mutis yaitu kepentingan pelestarian alam, silvopastur dan pertambangan. Tiga aktor utama yang terlibat keras dalam pertarungan kepentingan tersebut antara lain pertama, Balai Besar Konservasi Sumber Daya Alam Nusa Tenggara Timur (BBKSDA NTT) yang berkepentingan terhadap kelestarian hutan, kedua yaitu masyarakat sekitar hutan terhadap silvopastur untuk mempertahankan hidup, dan ketiga adalah Dinas Pertambangan berkepentingan terhadap hasil tambang.

Terkait kepentingan masyarakat, Coulibaly-Lingani et al (2011) menyatakan bahwa masyarakat lokal Gunung Mutis, telah sejak lama menggembala di kawasan hutan. Hutan berfungsi sebagai sumber pakan ternak dan sebagai areal penggembalaan. Konflik kepentingan antara pihak kehutanan dengan masyarakat yang menyangkut areal penggembalaan terus berlanjut. Sedangkan konflik antara pihak kehutanan dengan 
pertambangan relatif terselesaikan dengan kebijakan pelarangan tambang di cagar alam tersebut.

Menurut Rooswiadji (1999) kawasan Cagar Alam Gunung Mutis merupakan salah satu kawasan hutan yang khas di Nusa Tenggara karena memiliki tegakan ampupu (Eucalyptus urophylla) yang seragam dan relatif utuh. Topografi kawasannya adalah perbukitan dengan kemiringan hingga 60 persen dan beriklim sejuk dengan curah hujan rata-rata 1500-2000 mm/tahun. Gunung Mutis merupakan hulu tiga sungai besar yang menjadi sumber pemenuhan kebutuhan air bagi masyarakat di Pulau Timor bagian barat. Ketiganya adalah Noelmina, Benain dan Noebesi. Sistem ekologi yang unik tersebut menjadikan kawasan hutan Gunung Mutis sebagai hutan alam ampupu terluas di Indonesia.

Berdasarkan sifatnya yang khas dan fungsinya yang penting, sekitar $12.000 \mathrm{Ha}$ dari kawasan tersebut ditetapkan pemerintah menjadi cagar alam. Secara administratif, hutan Gunung Mutis terletak di Kecamatan Fatumnasi Kabupaten Timor Tengah Selatan (TTS) dan Kecamatan Miomafo Barat Kabupaten Timor Tengah Utara (TTU). Secara geografis, Cagar Alam Gunung Mutis terletak di antara $124^{\circ} 10^{\prime}-124^{\circ} 20^{\prime}$ BT dan $9{ }^{\circ} 30^{\prime}-9^{\circ} 40^{\prime}$ LS. Puncaknya berada di ketinggian 2.427 mdpl. Berdasarkan peta tanah 1:2.500.000 yang diterbitkan Lembaga Penelitian Tanah Bogor tahun 1968, tipe tanah di Gunung Mutis adalah tanah kompleks dengan bentuk pegunungan kompleks dan tanah mediteran yang berbentuk wilayah pegunungan lipatan.

Kawasan ini merupakan wilayah terbasah di Pulau Timor dengan lima bulan kering dan tujuh bulan basah. Pada NovemberMaret, kawasan ini menerima tiupan angin kencang disertai hujan lebat, yang terkadang menimbulkan bencana bagi masyarakat berupa tanah longsor, gagal panen dan rumah roboh. Di dalam kawasan terdapat 16 jenis burung 31 anak jenisnya, 15 jenis diantaranya tergolong berpopulasi rendah. Selain burung, adapula beberapa mamalia seperti babi hutan (Sus sp), kuskus (Phalanger orientalis), rusa (Cervus timorensis), monyet ekor panjang (Macaca fascicularis) dan landak (Nytrix sp).

Sesungguhnya, untuk mendukung kepentingan pelestarian alam di Cagar Alam Gunung Mutis, pemerintah telah mengeluarkan berbagai instrumen perundangan dengan tujuan utama membatasi dan membuat larangan kegiatan silvopastur. Peraturan perundang-undangan tersebut antara lain: (1) UU No. 41 Tahun 1999 tentang Kehutanan; (2) UU No. 5 Tahun 1990 tentang Konservasi Sumber Daya Alam; (3) PP No 68 Tahun 1998, tentang Kawasan Suaka Alam dan Kawasan Pelestarian Alam.

Langkah penyelamatanlain dari pemerintah adalah pada tahun 2012 areal hutan lindung Mutis Timau diubah menjadi Kesatuan Pengelolaan Hutan Lindung Model Mutis Timau (KPHL Mutis Timau) melalui Surat Keputusan Menteri Kehutanan No. 41/Menhut-II/2012, tanggal 2 Februari 2012, dengan luas wilayah 115.380 Ha. Perpaduan antara KPHL Mutis Timau dan Cagar Alam Gunung Mutis membentuk hutan yang berfungsi sebagai perlindungan flora, satwa, dan fungsi air. Namun beberapa kebijakan ini tetap saja gagal mengatasi kerusakan hutan, terutama karena kegiatan silvopastur atau penggembalaan liar.

Berkaitan dengan permasalahan yang dikemukakan di atas, tujuan penelitian ini adalah: (1) Mengkaji alasan masyarakat melakukan perlawanan terhadap kebijakan pemerintah pusat terkait silvopastur; (2) mengkaji ada atau tidaknya dampak negatif dari perlawanan terhadap implementasi kebijakan silvopastur.

\section{Metode Penelitian}

Penelitian dilakukan di Cagar Alam Gunung Mutis sebagai studi kasus dan lokasi dipilih secara purposif. Penelitian dilakukan 
Gambar 1.

\section{Lokasi Penelitian}

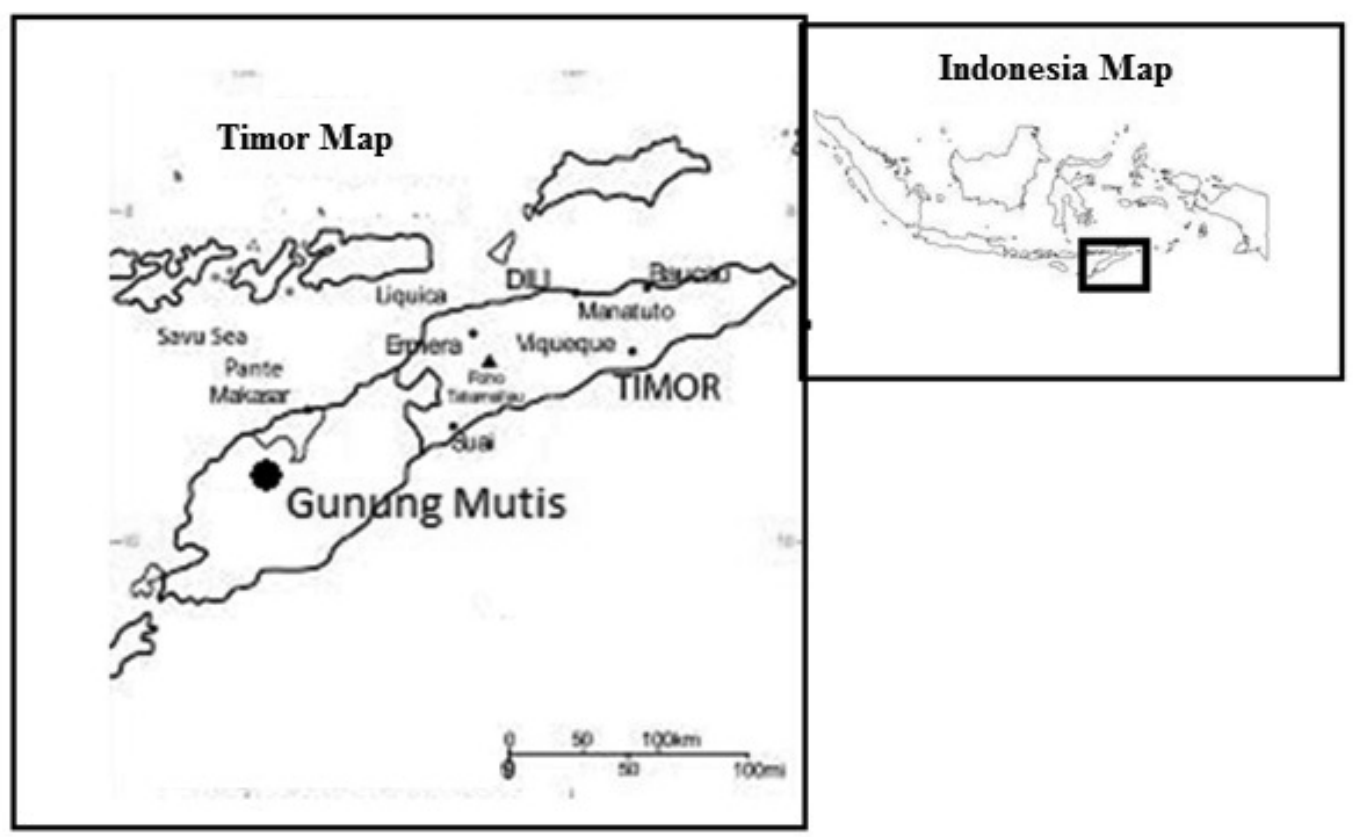

mulai Mei hingga Juni 2015. Wawancara dilakukan di tiga desa yang berbatasan langsung dengan lokasi cagar alam yaitu Desa Fatumnasi, Nenas, dan Bonleu dengan target informan kunci dari masyarakat, metode yang dipakai adalah snowball sampling.

Informan merupakan stakeholder Cagar Alam Gunung Mutis. Menurut Freeman (1984) stakeholder adalah pihak yang dipengaruhi oleh tindakan/kebijakan atau pihak yang mempengaruhi tindakan/kebijakan. Jumlah informan 20 orang terdiri atas 2 orang dari BBKSDA, 2 orang dari KPHL Mutis Timau, 2 orang dari Dinas Kehutanan Kupang, 2 orang dari Dinas Kehutanan Kab. Timor Tengah Selatan, 3 orang peternak/tokoh masyarakat dari Desa Fatumnasi, 3 peternak/tokoh masyarakat dari Desa Nenas, dan 3 orang peternak dari Desa Bonleu, 2 orang pengusaha dan 1 orang dari LSM/WWF.

Penelitian menggunakan metode eksplorasi kualitatif untuk memahami mengapa masyarakat lokal melakukan perlawanan terhadap larangan silvopastur. Penelitian ini juga menggunakan pendekatan teori akses dari Ribot \& Peluso (2003) untuk memahami apakah perlawanan tersebut berpengaruh terhadap implementasi kebijakan silvopastur. Melalui pendekatan ini, pihak yang dapat memanfaatkan cagar alam ditentukan oleh kemampuannya memanfaatkan cagar alam tersebut, sehingga tidak tergantung pada kepemilikan dari cagar alam tersebut.

Analisis data dilakukan secara deskriptif dengan mengekplorasi penyebab masyarakat melawan larangan silvopastur. Selain itu dilakukan analisis perlawanan tersebut berpengaruh atau tidak terhadap implementasi kebijakan silvopastur di Cagar Alam Gunung Mutis.

\section{Pembahasan}

Cagar Alam Gunung Mutis terletak di Pulau Timor Provinsi Nusa Tenggara Timur dengan luas 12.000 Ha ( Farida et al., 2005). Hutan di Gunung Mutis ditetapkan sebagai cagar alam pada tahun 1983 melalui SKMenteri Pertanian Nomor: 89/Kpts-II/1983 tanggal 2 Desember 1983. Berbatasan langsung dengan Cagar Alam Gunung Mutis, terdapat hutan 
lindung yang pada tahun 2012 ditetapkan sebagai Kesatuan Pengelolaan Hutan Lindung Model Mutis Timau melalui Keputusan Menteri Kehutanan Republik Indonesia Nomor SK.41/ menhut-II/2012 tentang Penetapan Wilayah Kesatuan Pengelolaan Hutan lindung (KPHL) Model Mutis Timau (Unit XIX) yang terletak di Kabupaten Kupang, Kabupaten Timor Tengah Selatan, dan Kabupaten Timor Tengah Utara, Provinsi Nusa Tenggara Timur.

Cagar Alam Gunung Mutis memiliki flora dan fauna endemik (Farida et al., 2005). Kerapatan tegakan rapatnya sampai padang rumput. Potensi rumput terdapat pada tegakan hutan yang sedang hingga rendah. Rumput tersebut dimanfaatkan masyarakat untuk penggembalaan secara liar. Penggembalaan di dalam hutan dikenal dengan istilah silvopastur. Menurut Houx III et al. (2013) silvopastur merupakan sistem tanaman yang mengintegrasikan tanaman hutan, rumput dan ternak.

Penelitian ini menggunakan metode eksplorasi kualitatif untuk memahami mengapa masyarakat lokal melakukan perlawanan terhadap larangan silvopastur di cagar alam Gunung Mutis. Selain itu penelitian ini menggunakan pendekatan teori akses (Ribot \& Peluso, 2003) untuk memahami apakah perlawanan tersebut berpengaruh terhadap kebijakan silvopasture.

Dari hasil wawancara diketahui bahwa para peternak tidak setuju dengan adanya larangan silvopastur, alasannya adalah: (1) masyarakat telah lama melakukan silvopastur di Gunung Mutis, sejak jauh sebelum kawasan tersebut ditetapkan sebagai cagar alam; (2) masyarkat setempat memiliki budaya ternak lepas; (3) kegiatan silvopastur merupakan sumber utama pendapatan masyarakat; (4) proses pembuatan kebijakan tidak menyertakan masyarakat lokal.

Terdapat pihak lain yang setuju dengan larangan silvopastur yaitu pemerintah dan LSM seperti Balai Besar Konservasi Sumber Daya Alam, Kesatuan Pengelolaan Hutan Lindung Mutis Timau, Dinas Kehutanan Kupang, dan Dinas Kehutanan Timor Tengah Selatan. Sikap stakeholder terhadap kebijakan silvopastur dapat dilihat pada Tabel 1.

Meskipun jumlah pihak yang setuju terhadap kebijakan silvopastur lebih banyak dibanding yang tidak, kebijakan tersebut tetap tidak dapat berjalan. Fenomena ini dianalisis dengan menggunakan pendekatan teori akses ( Ribot \& Peluso 2003). Hasil penelitian menunjukan bahwa peternak dapat melakukan silvopastur di cagar alam Gunung Mutis karena memiliki kemampuan untuk mengakses rumput yang berada di sana. Kemampuan tersebut berkaitan dengan budaya dan kondisi sosial ekonomi masyarakat sekitar.

Masyarakat melawan larangan silvopastur karena sejarah penggembalaan di Gunung Mutis telah lama berlangsung. Menurut Ostrom (2009) sejarah penggunaan lahan mempengaruhi implementasi dari suatu aturan. Penggembalaan liar dilakukan oleh masyarakat yang memiliki ternak lebih dari dua ekor, kegiatan ini dilakukan karena peternak tidak mampu mencari pakan apabila

Tabel 1.

Sikap Stakeholder terhadap Kebijakan Silvopastur

\begin{tabular}{clccc}
\hline No & \multicolumn{1}{c}{ Stakeholder } & Mendukung & Netral & Menolak \\
\hline 1 & Peternak & & & X \\
2 & BBKSDA & X & & \\
3 & WWF & X & & \\
4 & Dinas Kehutanan Kupang & X & & \\
5 & Dinas kehutanan TTS & $X$ & & \\
6 & KPHL & & $X$ & \\
7 & Pengusaha & & \\
\hline
\end{tabular}


jumlah ternaknya banyak. Hasil wawancara menunjukan bahwa seorang peternak dapat memiliki hingga tujuh puluh ekor ternak yang digembalakan secara liar.

Menurut Rooswidji (1999) Pegunungan Mutis dengan hutan dan padang rumput yang luas merupakan daerah potensial bagi usaha peternakan. Jenis ternak yang dipelihara oleh masyarakatnya terdiri dari ternak besar, ternak kecil dan unggas. Jenis ternak besar adalah sapi (Bos indicus), kuda (Equus cabalus) dan kerbau (Bos bubalis) sedangkan jenis ternak kecil antara lain babi (Sus sp), kambing (Capra $s p$ ) dan beberapa jenis unggas.

Menurut Piggin (2003) masyarakat Nusa Tenggara Timur telah melakukan kegiatan silvopastur sejak tahun 1912, sedangkan kawasan Gunung Mutis ditetapkan sebagai cagar alam tahun 1983. Pola penyebaran dan pengembangan sapi yang diterapkan oleh Belanda dilakukan melalui berbagai jalur, yakni dari raja yang disebut "usif" kepada bawahannya yang disebut "temukung" dan akhirnya ke masyarakat (Rooswiadji, 1999). Belanda mendistribusikan sapi melalui bantuan orang Tionghoa, yang kemudian didistribusikan kepada masyarakat. Sapi tersebut ditukar dengan dua ekor kerbau. Sesuai perkembangan zaman, populasi kerbau menurun dan populasi sapi meningkat.

Ternak yang dominan digembalakan adalah sapi Bali. Hewan ini dipilih karena dapat digembalakan secara liar, relatif mudah ditangkap, dan jumlah pakan yang diperlukan relatif sedikit dibandingkan varietas sapi lain. Ternak ditandai oleh pemiliknya pada kulit atau telinga agar tidak hilang dan membedakan dengan sapi milik orang lain.

Masyarakat menolak larangan silvopastur karena adanya budaya ternak liar, yang merupakan salah satu budaya mereka. Budaya masyarakat berperan dalam kegiatan konservasi hutan (Gueze et al, 2015). Pada beberapa kasus, budaya masyarakat dapat berdampak positif maupun negatif terhadap ekologi hutan. Budaya tersebut sulit diubah karena telah berlangsung lama dan masyarakat menikmatinya. Masyarakat tidak memiliki budaya mencari pakan ternak untuk ternak miliknya, berbeda dengan peternak Pulau Jawa yang terbiasa mencarikan pakan untuk hewan ternaknya. Pola penggembalaan liar tidak memerlukan tenaga kerja dalam jumlah banyak, sehingga biaya produksinya lebih rendah.

Budaya beternak masyarakat Nusa Tenggara Timur cukup kuat dan telah berlangsung ratusan tahun (Fuah et al,. 2014). Hal ini merupakan bentuk adaptasi masyarakat setempat terhadap kondisi iklimnya yang kering. Umumnya mereka mengandalkan hidup dari bercocok tanam, namun iklim yang kering menyebabkan kebutuhan pangan keluarga tidak terpenuhi. Kegitan peternakan dilakukan untuk mengatasi hal tersebut. Hasil ternak dijual untuk memenuhi kebutuhan pangan dan kebutuhan lainnya bagi keluarga.

Selain budaya penggembalaan liar, adapula kearifan lokal di sekitar Cagar Alam Gunung Mutis. Masyarakat melakukan silvopastur tanpa merusak pohon di hutan. Hal ini menjadi salah satu argumentasi untuk menentang larangan silvopastur. Namun pihak BBKSDA tetap berpendapat silvopastur merusak hutan.

Penggembalaan liar memiliki beberapa keunggulan jika dibandingkan dengan peternakan dalam kandang. Pertama, lebih efisien dalam penggunaan tenaga kerja. Satu orang peternak dapat mengelola hingga 70 ekor, sedangkan peternak sistem kandang hanya mampu mengelola 2 ekor. Kedua, biaya tenaga kerja kecil. Biaya yang rendah membuat ternak dari Cagar Alam Gunung Mutis dapat dijual hingga ke Pulau Jawa dengan harga bersaing. Namun kelemahannya, silvopastur rawan tindakan pencurian dan kehilangan. Oleh karena itu penggembalaan liar hanya dapat dilakukan di Pulau Timor dan beberapa 
daerah di Indonesia dengan tingkat pencurian ternak yang rendah. Ditambah lagi, kualitas ternak tersebut rendah akibat dari kualitas pakan yg tidak baik dan rawan penyakit.

Adapula budaya memelihara ternak dalam jumlah besar, hal tersebut berkaitan dengan status sosial masyarakat setempat. Masyarakat lokal menganggap orang yang memiliki ternak banyak adalah orang kaya dan memiliki status sosial yang tinggi. Dalam hal ini kepemilikan ternak tidak ditujukan untuk kepentingan ekonomi namun lebih untuk status sosial. Umumnya yg memiliki jumlah ternak banyak adalah tokoh masyarakat. Pemerintah daerah telah berupaya mengubah pola ternak dari ternak lepas menjadi terikat, namun belum berhasil karena kebiasaan masyarakat yang susah berubah dan peternak kesulitan untuk mencari sendiri pakan untuk ternaknya.

Pihak Balai Besar Konservasi Sumber Daya Alam Nusa Tenggara Timur telah berupaya mengeluarkan ternak dari Cagar Alam Gunung Mutis tahun 1997 sampai dengan tahun 2003, dibantu WWF yang berkepentingan terhadap kelestarian cagar alam tersebut. Namun terjadi perlawanan dari masyarakat sehingga upaya tersebut dihentikan.

Perlawanan terhadap larangan silvopastur juga dikarenakan kondisi ekonomi masyarakat. Saat ini lapangan kerja di sekitar cagar alam sangat terbatas. Silvopastur merupakan salah satu sumber pendapatan utama masyarakat sekitar hutan.. Pemerintah dapat menghentikan silvopastur apabila ada alternatif lapangan kerja.

Proses terjadinya kebijakan silvopastur tidak melibatkan masyarakat lokal. Kebijakan tentang cagar alam berlaku secara nasional tanpa melihat konteks masyarakat lokal. Hal ini mengakibatkan masyarakat resisten terhadap kebijakan tersebut sehingga kebijakanpun sulit diterapkan. Kebijakan tersebut pun bertentangan dengan budaya lokal. Menurut Ostrom (2009) aturan yang tidak koheren dengan masyarakat lokal tidak akan berjalan, ditambah lagi Mendes (2006) menyebutkan bahwa kebijakan yang merugikan masyarakat dari sekitar hutan mendapat respon negatif dari masyarakat. Hanya kebijakan yang diterima oleh masyarakat lokallah yang dapat diimplementasikan dengan baik. Sehingga kegagalan implementasi kebijakan dapat diakibatkan oleh kendala feasibilitas, individu, dan dana (Mendes, 2006).

Kebijakan tentang cagar alam bersifat nasional. Masyarakat dilarang memasukan jenis-jenis eksotik ke dalam kawasan tersebut seperti sapi, kambing atau kuda. Di Pulau Jawa kebijakan tersebut dapat terlaksana karena masyarakat terbiasa dengan pola peternakan dalam kandang. Namun di cagar alam Gunung Mutis kebijakan tersebut sulit terlaksana karena masyarakat sekitar terbiasa melakukan penggembalaan liar. Oleh karena, agar kebijakan dapat terlaksana perlu dibuat kebijakan yang mempertimbangkan konteks lokal.

Perlawanan masyarakat lokal berpengaruh terhadap implementasi kebijakan silvopastur. Masyarakat tetap melakukan silvopastur meskipun dilarang. Demi memahami fakta ini dilakukan analisis dengan menggunakan pendekatan teori akses (Ribot \& Peluso, 2003). Masyarakat dapat mengakses rumput yang berada di cagar alam karena memiliki kemampuan untuk mengakses sumber daya alam, berkaitan dengan kekuatan yang dimiliki para peternak, seperti materi, budaya dan kondisi ekonomi (Ribot \& Peluso, 2003).

Kekuatan stakeholder berkaitan dengan jumah dana dan tenaga kerja yang dialokasikan untuk mencapai tujuan. Stakeholder yang memiliki kekuatan yang lebih tinggi adalah yang dapat mengakses sumber daya alam. Menurut Reed et al. (2009) kekuatan stakeholder turut menentukan keberhasilan implementasi kebijakan. BBKSDA adalah satu-satunya pihak pemerintah yang mengalokasikan tenaga kerja untuk menjaga hutan, itupun hanya 2 petugas. 
Tabel 2.

Alokasi Tenaga Kerja di Cagar Alam Gunung Mutis

\begin{tabular}{lcc}
\hline \multicolumn{1}{c}{ Stakeholder } & Kekuatan & Aksi \\
\hline Peternak & 400 peternak & Beternak tiap hari \\
Dinas Kehutanan Kupang & 0 & \\
Dinas Kehutanan Timor Tengah Selatan & 0 & \\
KPHL Mutis Timau & 0 & Menjaga hutan \\
BBKSDA & 2 & Membantu mengeluarkan \\
WWF & 0 & peternak tahun 1997-2003 \\
\hline
\end{tabular}

Jumlah itu tidak sebanding dengan jumlah peternak yang mencapai 400 orang, sehingga mereka dapat memasuki cagar alam dengan leluasa. Sementara itu stakeholder lainnya tidak memiliki kekuatan di lapangan, pengaruh masyarakat sekitar hutan adalah yang terkuat sehingga praktik silvopastur berjalan sesuai keinginan masyarakat. Suatu saat apabila pengaruh BKSDA dan Dinas Kehutanan lebih kuat dari masyarakat maka praktik silvopastur di lokasi penelitian dapat dihentikan.

Di sisi lain, peternak lokal merupakan stakeholder yang harus diberi perhatian. Matilainen (2014) berpendapat bahwa stakeholder dapat berperan dalam kelangsungan suatu kegiatan. Hubungan yang buruk antara pihak BBKSDA dan peternak lokal dapat menghentikan kegiatan pelestarian hutan di Cagar Alam Gunung Mutis. Peternak lokal juga berperan dalam keberhasilan implementasi kebijakan.

Kawasan hutan merupakan kawasan yang bersifat terbuka. Keutuhan kawasan hanya bisa tercapai jika tidak ada manusia yang berada di sekitar hutan. Dalam kasus Cagar Alam Gunung Mutis, mencegah kegiatan silvopastur sangatlah sulit. Luas dan arealnya yang bersifat terbuka menyebabkan silvopastur sulit dikontrol petugas. Kondisi ini memudahkan para peternak untuk mengakses rumput.

Kondisi hutan Cagar Alam Gunung Mutis merupakan areal open access. Masyarakat dan peternakmudah memasukinya. Kondisi tersebut membuat kelestarian hutan sangat tergantung pada masyarakat sekitar. Pemerintah harus membina masyarakat agar bersedia membantu melestarikan hutan dengan memelihara pohon di hutan tersebut. Partisipasi masyarakat dapat mencegah kerusakan hutan.

Pihak BBKSDA NTT, Dinas Kehutanan TTS, Dinas Kehutanan Kupang, dan KPHL Mutis belum menerapkan sanksi terhadap pelaku silvopastur karena beberap alasan. Pertama, penerapan sanksi dikhawatirkan memacu gejolak sosial di masyarakat, dikhawatirkan terjadi konflik antara petugas di lapangan dengan masyarakat. Kedua, sanksi sulit diterapkan karena jumlah petugas di lapangan hanya sedikit. Cagar Alam Gunung Mutis hanya dijaga 2 petugas sehingga sulit mencegah peternak masuk.

Hubungan antar-stakeholder dapat mempengaruhi implementasi kebijakan silvopastur. Zhou et al (2014) menyatakan bahwa sering terjadi konflik antara pengelola kawasan hutan konservasi dengan masyarakat setempat akibat adanya kebijakan yang merugikan masyarakat. Dalam kasus ini, hubungan yang buruk antara pihak BBKSDA dan masyarakat disebabkan oleh larangan silvopastur. Masyarakat tetap melakukan silvopastur meski telah dilarang.

Menurut Reed et al (2009) hubungan antarstakeholder dapat dibagi menjadi kooperatif, konflik dan komplementer. Berdasarkan kepentingannnya, hubungan antara peternak dan pemerintah adalah konflik. Jika satu pihak mencapai tujuan maka pihak lain tidak. Hubungan antara Dinas Kehutanan Kupang, Dinas Kehutanan TTS, KPHL Mutis 
Timau dan BBKSDA adalah kooperatif. Sedangkan hubungan antara pemerintah dengan LSM adalah komplementer. Namun, meskipun banyak pihak yang kooperatif dengan pemerintah, kekuatan yang dimiliki lebih rendah dibandingkan kekuatan peternak. Tujuan peternak agar dapat menggembala tercapai sedangkan tujuan pemerintah tidak.

Hubungan antar-stakeholder dapat berubah seiring perubahan kepentingan ( Zhaou et al., 2014). Pemerintah bisa mengizinkan silvopastur di cagar alam selama kelestarian hutan terjaga. Jika ini terjadi maka hubungan antara peternak dengan pemerintah dapat berubah menjadi kooperatif. Perlu dilakukan lobi antara pemerintah dengan peternak untuk menjelaskan tugas dan tanggung jawab masing-masing. Cara ini merupakan cara moderat untuk mencapai tujuan kedua belah pihak. Persepsi masyarakat mempengaruhi implementasi kebijakan dalam bidang silvopastur (Cao et al, 2010). Implementasi kebijakan tersebut tidak terlaksana karena masyarakat merasa silvopastur tidak merusak hutan. Selain itu sebagian besar peternak tidak mengetahui jika penggembalaan liar di cagar alam dilarang.

Menurut Gossum et al. (2010) penolakan masyarakat lokal menyebakan kebijakan pengelolaan sumber daya hutan tidak dapat diimplementasikan dengan baik. Perlu dilakukan sosialisasi dengan masyarakat untuk mengurangi penolakan terhadap suatu kebijakan. Upaya tersebut telah dilakukan oleh pihak BBKSDA dan KPHL Mutis Timau, namun sampai saat ini belum berhasil. Yang dapat dilakukan saat ini adalah memonitor jumlah ternak dan kegiatan para peternak agar tidak merusak hutan.

Menurut Gueze et al. (2015) kearifan lokal berhubungan erat dengan biodiversitas kawasan hutan. Cagar Alam Gunung Mutis hingga saat ini memiliki keanekaragaman flora dan fauna yang tinggi dan merupakan habitat dari berbagai jenis burung dan mamalia. Salah satu hewan endemik adalah kuskus dan flora dominannya adalah ampupu (Eucalyptus urophylla). Keanekaragaman tersebut dapat terjaga karena para peternak memiliki kearifan lokal untuk tidak merusak hutan walaupun tidak dijaga pemerintah. Kearifan lokal tersebut harus tetap dipelihara guna kepentingan kelestarian hutan.

\section{Kesimpulan}

Perlawanan masyarakat lokal terhadap kebijakan pemerintah dikarenakan kegagalan dari kebijakan tersebut dalam memahami konteks lokal, kerangka kebijakan konservasi cenderung tidak aspiratif dan menegasikan keberadaan sistem mata pencaharian lokal dan dimensi historis klaim properti masyarakat. Konteks lokal yang dimaksud adalah budaya masyarakat dan kondisi sosial ekonomi. Perlawanan tersebut berpengaruh terhadap implementasi kebijakan karena masyarakat lokal mampu mengakses sumber daya hutan. Hasil penelitian ini menyarankan agar pemerintah membuat kebijakan yang disesuaikan dengan konteks masyarakat lokal. Kebijakan tentang silvopastur yang bersifat nasional harus ditinjau ulang.

\section{Daftar Pustaka}

Canova, N., Hickey GM. (2012). Understanding The Impacts of The 2007-2008 Global Financial Crisis on Sustainable Forest Management in The Brazilian Amazon: A Case Study. Ecological Economics. 83 , 19-31 Cao S., Wang X., Song Y., Chen L., Feng Q. (2010). Impacts of The Natural Forest Conservation Program on The Livelihoods of Residents of Northwestern China: Perceptions of Residents Affected by The Program. Ecological Economics. 69,1454-1462

Farida, W.R., Triono T., Handayani T.H., Ismail. (2005). Pemilihan Jenis Tumbuhan Sumber Pakan dan Tempat Bersarang Kuskus (Phalangar sp) di Cagar Alam Gunung Mutis, Nusa Tenggara Timur. Biodiversitas. $6,50-54$ 
Freeman, R.E. (1984). Stategic Management: A Stakeholder Approach. London : Pitman Publishing Inc

Fuah, A.M., Siregar, H., Winarno. (2014). Peternakan Terpadu; Konsep, Rancang dan Aplikasi. Bogor : IPB Press.

Gintings, N., Lai, C.K. (1994). Agroforestry in Asia and The Pacific: With Special Reference to Silvopasture Systems. Dalam : J.W. Copland, J.W., Djanegara, A, Sabrani, M. Ed. Agroforestry and Animal Production For Human Welfare. Canberra: ACIAR. .

Gossum, P.V., Ledene, L., Bas Arts Vreese R.D., Verheyen, K. (2008). Implementation Failure of The Forest Expansion Policy in Flanders (Northern Belgium) and the Policy Learning Potential. Forest Policy and Economics. 10, 515-522

Gueze, M., Luz, AC., Paneque-Gálvez, J., Macia, MJ., Orta-Martinez, M., Pino, J., Reyes-Gacia, V. (2015). Shifts in Indigenous Culture Relate to Forest Tree Diversity: A Case Study From The Tsimane', Bolivian Amazon. Biological Conservation. 186, 251-259

Gossum, PV., Arts, B., Laar, JV., Verheyen, K.. (2010). Implementation of The Forest Expansion Policy in The Netherlands in The Period 1986-2007: Decline in Success?. Land Use Policy. 27, 1171-1180

Hickey, G.M., Innes, J.L., Kozak, R.A. (2007). Monitoring and Information Reporting for Sustainable Forest Management: A Regional Comparison of Forestry Stakeholder Perceptions. Journal of Environmental Management. 84, 572-585

Houx, J.H., McGraw, R.L., Garret, H.E., Kallebach, R.I., Fritschi, F.B., Rogers, W. (2013). Extent of Vegetation-Free Zone Necessary for Silvopasture Establishment of Eastern Black Walnut Seedlings in Tall Fescue. Agroforestry Systems. 87, 73-80

Keputusan Menteri Kehutanan Republik Indonesia Nomor SK.41/menhut-II/2012 tentang Penetapan Wilayah Kesatuan
Pengelolaan Hutan lindung (KPHL) Model Mutis Timau (UnitXIX) Kabupaten Kupang, Kabupaten Timor Tengah Selatan, dan Kabupaten Timor Tengah Utara, Provinsi Nusa Tenggara Timur.

Keputusan Menteri Pertanian NO. 89/KptsII/1983, tertanggal 2 Desember 1983, tentang Cagar Alam Mutis seluas \pm 12.000 hektar.

Mendes, A.M.S.C., (2006). Implementation Analysis of Forest Programmes: Some Theoretical Notes and an Example. Forest Policy and Economics. 8, 512-528.

Naka, Kozma., Hammett, AL., Stuart, WB. (2000). Constraints and Opportunities to Forest Policy Implementation in Albania. Forest Policy and Economics. 1, 153-163

Peraturan Pemerintah Republik Indonesia Nomor 28 Tahun 2011 tentang Pengelolaan Kawasan Suaka Alam dan Kawasan Pelestarian Alam.

Peraturan Menteri Lingkungan Hidup dan Kehutanan nomor P.14/Menlhk-II/2015 tentang Tata Cara Pemberian Izin Usaha Pemanfaatan Kawasan Silvopastur pada Hutan Produksi.

Piggin, C. (2003). The Role of Leucaena in Swidden Cropping and Livestock Production in Nusa Tenggara Timur Province, Indonesia. ACIAR Proceedings No. 113

Purnomo, H., Suyamto, D., Abdullah, L., Irawati, RH. (2012). REDD+ Actor Analysis and Political Mapping: An Indonesian Case Study. International Forestry Review. 14, 74-89.

Ostrom, E. (2009). A General Framework for Analyzing Sustainability of SocialEcological Systems. Science. 325, 419-421.

Ribot, J.C., Peluso, N.,L. (2003). A Theory of Access. Rural Sociology. 68(2) :153-181.

Reed, MS., Graves, A., Dandy, N., Posthumus, H., Hubacek, K., Morris, J. (2009). Who's In and Why? A Typology of Stakeholder Analysis Methods for Natural Resource Management. Journal of Environmental Management. 90, 1933-1949. 
Rooswiadji, T. A. (1999). Laporan Penelitian Aspek Ekonomi dan Budaya Pola Ternak Lepas dalam Kaitannya dengan Pelestarian Sumber Daya Alam di Kawasan Gunung Mutis. Tidak diterbitkan.

Undang-Undang Republik Indonesia Nomor 5 Tahun 1990 tentang Konservasi Sumber Daya Alam Hayati dan Ekosistemnya.
Zhou, D., Ziyan, W., Lessoie, J., Wang, X., Sun, L. (2014). Changing Stakeholder Relationships in Nature Reserve Management: A Case Study on Snake Island-Laotie Mountain National Nature Reserve, Liaoning, China. Journal of Environmental Management 146: 292-302. 